\title{
Impact of External Radiotherapy on Survival after Stage I Endometrial Cancer: Results from a Population-Based Study
}

Pierre-Marie Tebeu ${ }^{1,45 *}$, Helena M Verkooijen ${ }^{2}$, Youri Popowski ${ }^{3}$, Christine Bouchardy ${ }^{2}$, Frank Ludicke ${ }^{4}$, Massimo Usel ${ }^{2}$ and Attila L Major ${ }^{1,4}$

${ }^{1}$ Department of Obstetrics and Gynaecology, Geneva University Hospitals, Switzerland

${ }^{2}$ Geneva Cancer Registry, Institute for Social and Preventive Medicine, Geneva University, Switzerland

${ }^{3}$ Department of Radiation Oncology, Geneva University Hospitals, Switzerland

${ }^{4}$ Fondation pour Recherches Médicales, University of Geneva Switzerland

${ }^{5}$ Department of Obstetrics and Gynaecology, Yaoundé University Hospitals, Cameroon

\begin{abstract}
Purpose: To assess the impact of external radiotherapy on the survival of patients with early stage endometrial cancer in a population-based setting.

Patients and methods: Using information from the Geneva Cancer Registry, we identified all patients who underwent operations for endometrial cancer between 1980 and 1996. We excluded patients with tumours that had spread beyond the uterus, patients without myometrial invasion and patients with poorly differentiated, deeply invasive tumours. Adjusting for other prognostic variables, a Cox proportional hazards analysis was used to calculate the diseasespecific risks and the overall mortality risks in patients treated with brachytherapy or external radiotherapy compared with non-irradiated patients. Stratified analyses were performed for patients with 'low-risk' (superficial myometrial invasion, grades 1-2) and 'high-risk' (superficial invasion grade 3 or deep invasion grades 1-2) tumours.
\end{abstract}

Results: For the 162 patients with low-risk tumours, external radiotherapy was significantly associated with an increased overall mortality (hazard ratio [HR]: $6.4,95 \% \mathrm{Cl}: 1.3-30.2$ ) and endometrial cancer mortality (HR: $9.4,95 \%$ $\mathrm{Cl}$ : 1.0-86.7). In the group of patients with high-risk tumours $(n=108)$, neither brachytherapy nor external radiotherapy modified the endometrial cancer mortality risk.

Conclusion: External radiotherapy does not reduce mortality from early stage endometrial cancer and is associated with a significantly increased overall and endometrial cancer mortality risk among patients with superficially invasive grade $1-2$ tumours.

Keywords: Endometrial cancer; Radiotherapy; Survival

\section{Introduction}

Endometrial cancer is the most common genital tract malignancy in Western countries [1], and its incidence has increased considerably in recent decades [2]. More than $75 \%$ of endometrial cancers are still confined to the uterus at diagnosis (stage I) $[3,4]$. Among the most important predictors of local and distant recurrence for stage I tumours are the level of differentiation and the depth of the myometrial invasion [5].

Standard treatment for stage I endometrial cancer is hysterectomy with bilateral oophorosalpingectomy [6]. Postoperative radiotherapy is often included in the treatment to prevent loco-regional relapse. Four randomised clinical trials evaluated the impact of post-operative radiotherapy on the outcome in early stage endometrial cancer [7-10]. The Gynaecologic Oncology Group randomised patients with stage IB ( $<50 \%$ myometrial invasion), stage IC ( $\geq 50 \%$ myometrial invasion) and occult stage II (microscopic invasion of the cervix) endometrial cancer to postoperative external radiotherapy or surgery alone. They confirmed the results of the Aalders's trial and the PORTEC trial $[8,10]$ and many other single-centre observational studies by showing that external radiotherapy reduces the risk of loco-regional recurrence [8$15]$.

However, no study has shown a significant benefit of external radiotherapy on overall or disease-specific survival. In fact, several studies, including the Aalders's and PORTEC randomised trials, have shown non-significant trends towards poorer disease-specific survival among early stage endometrial cancer patients who were treated with external radiotherapy, particularly among patients with low-risk lesions (low grade and superficial myometrial invasion) [9,10,12-15].
It is important to confirm the results of randomised controlled trials in daily practice settings because randomised controlled trials are generally executed in specialised centres and mainly involve experts and highly dedicated physicians. Therefore, we exploited our population-based cancer registry data to evaluate the impact of external radiotherapy and brachytherapy on the survival of patients who underwent surgery for stage I endometrial cancer in the Swiss canton of Geneva.

\section{Materials and Methods}

We used data from the Geneva Cancer Registry to identify all female residents of the canton of Geneva who were diagnosed with corpus uteri cancer between 1980 and $1996(\mathrm{n}=731)$. We excluded patients with the following clinical characteristics: invasive malignancies that occurred within the five years prior to, or six months after the diagnosis of endometrial cancer $(n=74)$; lack of surgical treatment of their endometrial cancer $(n=87)$; and uterine sarcomas $(n=41)$. We limited

*Corresponding author: Pierre Marie Tebeu, MD MPH, Department of Obstetrics and Gynaecology, University Teaching Hospital, Switzerland, Tel: 00237776755 33; E-mail: pmtebeu@yahoo.fr

Received October 03, 2010; Accepted December 02, 2010; Published December 15,2010

Citation: Tebeu PM, Verkooijen HM, Popowski Y, Bouchardy C, Ludicke F, et al. (2011) Impact of External Radiotherapy on Survival after Stage I Endometrial Cancer: Results from a Population-Based Study. J Cancer Sci Ther 3: 041-046. doi:10.4172/1948-5956.1000055

Copyright: @ 2011 Tebeu PM, et al. This is an open-access article distributed under the terms of the Creative Commons Attribution License, which permits unrestricted use, distribution, and reproduction in any medium, provided the original author and source are credited. 
our study to patients with endometrial cancer that was confined to the uterus (regardless of the presence of tumour cells in the peritoneal washing fluid) [16]; 122 patients with more advanced stages were excluded. We excluded the 95 women with stage IA endometrial cancer (i.e., no invasion of the myometrium) because it is generally accepted that these women do not need radiotherapy. Similarly, 20 women with poorly differentiated tumours with greater than $50 \%$ myometrial invasion (stage IC grade 3) were also excluded because adjuvant therapy is commonly indicated for these women. We excluded an additional 22 women with missing information on the histology or grade of the tumour or the type of radiotherapy. The remaining 270 patients were included in the study.

The tumours were surgically staged and coded according to the FIGO (Fédération Internationale de Gynécologie et d'Obstétrique) system from 1988. Surgical treatment generally consisted of hysterectomy and oophorosalpingectomy. Lymphadenectomy was not routinely performed.

Geneva University Hospitals have the only radiation therapy centre in this canton, and every patient treated for endometrial cancer underwent radiotherapy there. All patients underwent a fluoroscopic simulation prior to radiotherapy. Simulation films were obtained for the anterior field and one lateral field. During the first week of radiotherapy, the position of the radiation fields was controlled by performing gammagraphies.

External radiotherapy was delivered using a 4 field technique (box); 26 fractions (range $24-28$ ) were provided with an average dose per fraction of 1.8 Gray (Gy) (range 1.8 - 2.0 Gy) and with an average cumulative dose of $48 \mathrm{~Gy}$ (range 45 - $50 \mathrm{~Gy}$ ). The energy varied between 6 and 18 Megavolts.

Brachytherapy was performed using either Caesium 137 or Iridium 192; $75 \%$ of the patients were treated with Caesium 137. The mean doses were 43.8 for Caesium 137 (in general, prescribed in one fraction) and 19 Gy for Iridium 192, which was prescribed in 3 fractions. Doses were delivered at a $5-\mathrm{mm}$ depth below the mucosal surface on a $3-\mathrm{cm}$ length of the vaginal vault. For the purpose of this study, we categorised the type of radiotherapy as no radiotherapy, brachytherapy, or external radiotherapy with or without brachytherapy.

Histological type and degree of differentiation were coded according to the International Classification of Diseases for Oncology [17]. All pathology reports were reviewed. Stages IB and IC are also described as conditions with superficial and deep invasion, respectively?

Based on previous studies $[9,18]$, we regrouped patients into 'low-risk' and 'high-risk' tumour profiles according to the degree of myometrial invasion and tumour differentiation. The low-risk group included patients with well or moderately differentiated tumours with less than 50\% myometrial invasion (stage IB (superficial invasion), grades 1 and 2). The high-risk group included 108 patients with either poorly differentiated tumours with less than $50 \%$ myometrial invasion (stage IB, grade 3 ) or well or moderately differentiated tumours $50 \%$ or more myometrial invasion (stage IC (deep invasion), grades 1 and 2).

Other variables of interest included the following: age at diagnosis $(<50,50-69, \geq 70$ years), healthcare sector (private clinics vs. public hospitals) and period of diagnosis (1980-87, 1988-96). The data on the survival were derived from the Geneva Cancer Registry and included vital status, date of death or date of departure from the canton (regularly and systematically obtained from the Cantonal Population Office). In addition to passive follow-up (routine examination of death certificates and hospital records), an active follow-up was routinely performed each year using the files from the Cantonal Population Office. The cause of death was systematically recorded, and specially trained medical staff routinely validated the cause of death by consulting the medical files or by sending a questionnaire to the treating physician.

\section{Statistical analyses}

Comparison of patients and tumour characteristics according to type of radiotherapy was performed using a chi-square test for heterogeneity. Using the actuarial method, we calculated the five-year overall survival rates considering all deaths that occurred in the cohort and the five-year disease-specific survival rates considering only deaths from endometrial cancer. We identified factors that were significantly associated with survival by means of a univariate Cox proportional hazards analysis (unadjusted hazard ratios). To identify significant and independent predictors of survival, we performed a multivariate Cox proportional hazards analysis, adjusting for age and all factors that were significantly linked to mortality in the univariate analysis (adjusted hazard ratios). We performed these analyses for both overall mortality and endometrial cancer-specific mortality. We repeated these analyses excluding patients with papillary and clear cell carcinoma because these histologies are associated with more aggressive tumour behaviour. Disaia Statistical analyses were performed with SPSS (version 11.5), and the differences were considered statistically significant if the twosided $\mathrm{p}$ value was $<0.05$.

\section{Results}

Of the 270 women included in this study, 87 (32\%) did not undergo radiotherapy, $94(35 \%)$ received only brachytherapy, and 89 (33\%) were treated with external radiotherapy with or without brachytherapy. Table 1 describes the demographic, tumour and treatment characteristics according to the type of radiotherapy. Women who received external radiotherapy were on average 4 years younger than the non-irradiated women. The proportion of patients treated without radiotherapy increased over the study period; between 1980 and 1987, 23\% were not irradiated vs. $40 \%$ between 1988 and 1966. The proportion of patients treated with brachytherapy decreased from $43 \%$ to $28 \%$, and the proportion of patients treated with external radiotherapy remained relatively stable. Patients treated in private clinics were less often irradiated, whereas patients treated in public hospitals received brachytherapy more frequently. We observed no significant differences in the surgical treatment between non-irradiated and irradiated patients, and the majority ( $94 \%$ on average) of patients were treated with hysterectomy and bilateral oophorosalpingectomy. Only 3 patients (1\%) underwent lymphadenectomy.

The patients treated with external radiotherapy had a less favourable tumour profile. Only 26 (29\%) of them had low risk disease (i.e., superficial myometrial invasion, grades 1-2) compared to 75 (80\%) of the patients treated with brachytherapy and 61 (70\%) of the nonirradiated patients $(\mathrm{p}<0.0001)$.

The median follow-up was 118 months. Fourteen women (5\%) had less than five years of follow-up. Figure 1 presents the five-year overall survival curves according to type of radiotherapy. For non-irradiated patients, patients treated with brachytherapy, and patients treated with external radiotherapy with or without brachytherapy, the five-year overall survival rate was $87 \%$ (95\%CI: 80-94\%), 91\% (95\%CI: 86-97\%), and $84 \%$ (95\%CI: 76-92\%), respectively.

Table 2 shows the overall and endometrial cancer survival rates and the unadjusted and multi-adjusted mortality risks according to patient 
Citation: Tebeu PM, Verkooijen HM, Popowski Y, Bouchardy C, Ludicke F, et al. (2011) Impact of External Radiotherapy on Survival after Stage I Endometrial Cancer: Results from a Population-Based Study. J Cancer Sci Ther 3: 041-046. doi:10.4172/1948-5956.1000055

\begin{tabular}{|c|c|c|c|c|c|c|c|c|c|}
\hline & \multicolumn{6}{|c|}{ Radiotherapy } & & & \multirow{3}{*}{$\begin{array}{l}P \text {-value of chi-square } \\
\text { test for heterogeneity }\end{array}$} \\
\hline & \multicolumn{2}{|c|}{$\begin{array}{l}\text { No radiotherapy } \\
(\mathrm{n}=87)\end{array}$} & \multicolumn{2}{|c|}{$\begin{array}{l}\text { Brachytherapy } \\
(n=94)\end{array}$} & \multicolumn{2}{|c|}{$\begin{array}{l}\text { External }{ }^{a} \\
(n=89)\end{array}$} & \multicolumn{2}{|c|}{$\begin{array}{l}\text { Total } \\
(n=270)\end{array}$} & \\
\hline & $\mathbf{N}$ & $\%$ & $\mathbf{N}$ & $\%$ & $\mathbf{N}$ & $\%$ & $\mathbf{N}$ & $\%$ & \\
\hline Mean age (range) & 66.7 & $(38-91)$ & 64.9 & $(35-90)$ & 62.9 & $(33-81)$ & 64.8 & $(33-91)$ & \\
\hline \multicolumn{10}{|l|}{ Age group } \\
\hline $70+$ & 36 & 40 & 30 & 34 & 23 & 26 & 89 & 100 & .092 \\
\hline $50-69$ & 43 & 26 & 60 & 37 & 61 & 37 & 164 & 100 & \\
\hline$<50$ & 8 & 47 & 4 & 24 & 5 & 29 & 17 & 100 & \\
\hline \multicolumn{10}{|l|}{ Period of diagnosis } \\
\hline $1980-1987$ & 29 & 23 & 54 & 43 & 43 & 34 & 126 & 100 & .005 \\
\hline 1988-1996 & 58 & 40 & 40 & 28 & 46 & 32 & 144 & 100 & \\
\hline \multicolumn{10}{|l|}{ Healthcare sector } \\
\hline Private & 50 & 41 & 34 & 28 & 37 & 31 & 121 & 100 & .012 \\
\hline Public & 37 & 25 & 60 & 40 & 52 & 35 & 149 & 100 & \\
\hline \multicolumn{10}{|l|}{ Surgical treatment } \\
\hline $\begin{array}{l}\text { Hysterectomy with } \\
\text { annexectomy }\end{array}$ & 80 & 32 & 87 & 34 & 86 & 34 & 253 & 100 & .535 \\
\hline $\begin{array}{l}\text { Hysterectomy without or } \\
\text { unknown annexectomy }\end{array}$ & 7 & 41 & 7 & 41 & 3 & 18 & 17 & 100 & \\
\hline \multicolumn{10}{|l|}{ Tumour risk category ${ }^{b}$} \\
\hline Stage IB grade 1 & 52 & 44 & 55 & 47 & 10 & 9 & 117 & 100 & .000 \\
\hline Stage IB grade 2 & 9 & 20 & 20 & 44 & 16 & 36 & 45 & 100 & \\
\hline Stage IB grade 3 & 6 & 32 & 5 & 26 & 8 & 42 & 19 & 100 & \\
\hline Stage IC grade 1 & 14 & 22 & 9 & 14 & 40 & 63 & 63 & 100 & \\
\hline Stage IC grade 2 & 6 & 23 & 5 & 19 & 15 & 58 & 26 & 100 & \\
\hline \multicolumn{10}{|l|}{ Risk category ${ }^{c}$} \\
\hline Low risk & 61 & 38 & 75 & 46 & 26 & 16 & 162 & 100 & .000 \\
\hline High risk & 26 & 24 & 19 & 18 & 63 & 58 & 108 & 100 & \\
\hline
\end{tabular}

${ }^{\mathrm{a}}$ External $=$ external radiotherapy with or without brachytherapy

'Stage IB: myometrial invasion $<50 \%$; Stage IC: myometrial invasion $>=50 \%$

Low risk: (Stage IB grade 1 and 2), High risk: (Stage IB grade 3 and Stage IC grade 1 and 2)

Table 1: Patient, tumour and surgical characteristics according to type of radiotherapy.

and tumour characteristics. The patient and tumour characteristics that were associated with overall mortality in univariate analysis were sector of care and tumour profile (grade/myometrial invasion). After adjustment for age, sector of care, tumour profile and type of radiotherapy, tumour profile was still linked to overall mortality. In particular, patients with poorly differentiated, superficially invasive tumours had a five-fold increased risk of death from all causes (hazard ratio 5.1, 95\% CI: 1.3-19.8).

Table 2 also shows that among all patient and tumour characteristics, only tumour profile was linked to death from endometrial cancer in univariate analysis. After adjustment for age and type of radiotherapy, the risk of death from endometrial cancer remained significantly increased for patients with poorly differentiated, superficially invasive tumours (hazard ratio 8.8, 95\% CI: 1.9-40.1).

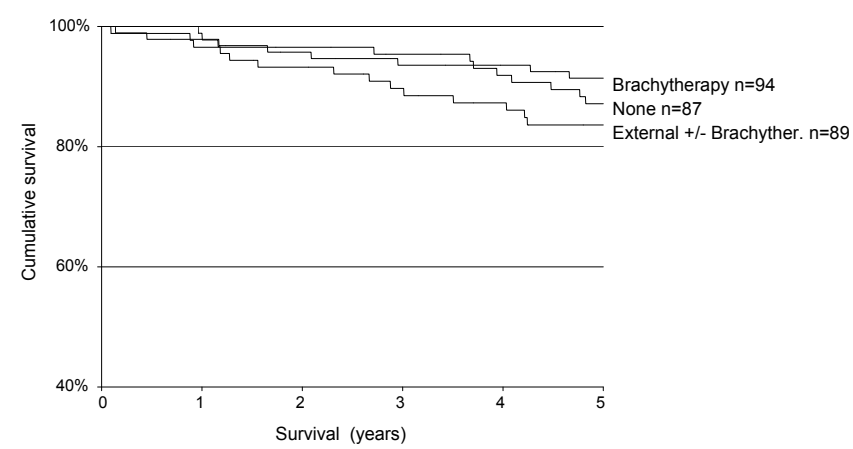

Figure 1: Five-year overall survival curves according to type of radiotherapy are presented. For non-irradiated patients, the five-year overall survival rate was $87 \%$, for patients treated with brachytherapy $91 \%$ and for patients treated with external radiotherapy with or without brachytherapy $84 \%$.

External+/-Brachyther = external radiotherapy with or without brachytherapy.
Table 3 shows the overall and disease specific survival rates and mortality risks according to type of radiotherapy for all patients combined and for low-risk and high-risk patients separately. For all patients combined, univariate analysis showed that neither brachytherapy nor external radiotherapy significantly modified overall or disease specific mortality risks. However, after adjusting for age, sector of care and tumour profile, we observed that patients treated with external radiotherapy had a 3.2-fold (multi-adjusted HR 3.2, 95\% CI: $1.2-8.7, p=0.020$ ) increased overall mortality risk compared to non-irradiated patients. After adjustment for age and tumour profile, the risk of death from endometrial cancer showed a 3.6-fold increase, which was not significant (hazard ratio 3.6, 95\% CI: 1.0-13.4, p=.059).

In the category of patients with low-risk tumours, external radiotherapy significantly increased both the overall mortality risk (multi-adjusted hazard ratio 6.4, 95\% CI: 1.3-30.2, p=0.020) and the risk of dying from endometrial cancer (multi-adjusted hazard ratio 9.4, 95\% CI: 1.0-86.7, p=0.047).

For high-risk patients, neither external radiotherapy nor brachytherapy modified the overall and endometrial cancer specific mortality risks. Compared to non-irradiated patients, those treated with brachytherapy were at a similar risk of dying from all causes (multi-adjusted hazard ratio 1.0, 95\% CI: 0.2-4.3. $\mathrm{p}=0.973$ ) and from endometrial cancer (multi-adjusted hazard ratio 1.6, 95\% CI: 0.3-8.1, $\mathrm{p}=0.564$ ). Similarly, external radiotherapy did not significantly modify the overall mortality risk (multi-adjusted hazard ratio $1.7,95 \% \mathrm{CI}$ : 0.5-6.3, $\mathrm{p}=0.396$ ) or the risk of dying from endometrial cancer (multiadjusted hazard ratio $1.9,95 \%$ CI: 0.4-9.1, $\mathrm{p}=0.453$ ).

When we repeated the analyses excluding the 10 patients with clear 
Citation: Tebeu PM, Verkooijen HM, Popowski Y, Bouchardy C, Ludicke F, et al. (2011) Impact of External Radiotherapy on Survival after Stage I Endometrial Cancer: Results from a Population-Based Study. J Cancer Sci Ther 3: 041-046. doi:10.4172/1948-5956.1000055

\begin{tabular}{|c|c|c|c|c|c|c|c|c|c|c|c|c|c|}
\hline & \multirow[b]{2}{*}{$\mathrm{N}$} & \multicolumn{6}{|c|}{ Overall mortality } & \multicolumn{6}{|c|}{ Mortality from endometrial cancer } \\
\hline & & Deaths N & $\begin{array}{l}\text { 5- year } \\
\text { survival } \\
(95 \% \mathrm{Cl})\end{array}$ & $\begin{array}{l}\text { Unadjusted } \\
\text { HR }(95 \% \mathrm{Cl})\end{array}$ & $P$-value & $\begin{array}{l}\text { Adjusted HR } \\
(95 \% \mathrm{Cl})^{\mathrm{a}}\end{array}$ & $P$-value & Deaths N & \begin{tabular}{|l} 
5-year \\
survival \\
$(95 \% \mathrm{Cl})$
\end{tabular} & $\begin{array}{l}\text { Unadjusted } \\
\text { HR }(95 \% \mathrm{CI})\end{array}$ & $P$-value & $\begin{array}{l}\text { Adjusted HR } \\
(95 \% \mathrm{Cl})^{\mathrm{b}}\end{array}$ & $P$-value \\
\hline \multicolumn{14}{|l|}{ Age } \\
\hline$<50$ & 17 & 1 & $94 \%(83-100)$ & $1^{\mathrm{c}}$ & & $1^{c}$ & & 1 & $94 \%(83-100)$ & $1^{c}$ & & $1^{\mathrm{c}}$ & \\
\hline $50-69$ & 164 & 7 & $96 \%(92-99)$ & $0.7(0.1-5.4)$ & .700 & $0.6(0.1-4.9)$ & .628 & 5 & $97 \%(94-100)$ & $0.5(0.1-4.0)$ & .491 & $0.5(0.6-4.2)$ & .512 \\
\hline $70+$ & 89 & 25 & $71 \%(62-81)$ & $5.0(0.7-37.0)$ & .114 & $4.4(0.6-33.1)$ & .155 & 13 & $84 \%(76-92)$ & $2.6(0.3-19.8)$ & .359 & $3.9(0.5-30.5)$ & .196 \\
\hline \multicolumn{14}{|l|}{ Period } \\
\hline 1980-1987 & 126 & 15 & $88 \%(82-94)$ & $1^{c}$ & & $1^{c}$ & & 9 & $93 \%(88-97)$ & $1^{c}$ & & $1^{c}$ & \\
\hline 1988-1996 & 144 & 18 & $87 \%(82-93)$ & $1.1(0.5-2.1)$ & .835 & $0.8(0.4-1.7)$ & .580 & 10 & $93 \%(88-97)$ & $1.0(0.4-2.4)$ & .982 & $0.5(0.2-1.5)$ & .217 \\
\hline \multicolumn{14}{|l|}{$\begin{array}{l}\text { Sector of } \\
\text { care }\end{array}$} \\
\hline Private & 121 & 9 & $92 \%(87-97)$ & $1^{c}$ & & $1^{c}$ & & 5 & $96 \%(92-100)$ & $1^{c}$ & & $1^{c}$ & \\
\hline Public & 149 & 24 & $84 \%(77-90)$ & $2.3(1.1-5.0)$ & .033 & $2.0(0 \cdot 8-5.0)$ & .150 & 14 & $90 \%(85-95)$ & $2.4(0.9-6.7)$ & .089 & $3.7(1.0-14.0)$ & .054 \\
\hline \multicolumn{14}{|l|}{ Risk category } \\
\hline 1b Grade 1 & 117 & 10 & $91 \%(86-96)$ & $1^{c}$ & & $1^{c}$ & & 3 & $97 \%(94-100)$ & $1^{c}$ & & $1^{c}$ & \\
\hline 1b Grade 2 & 45 & 7 & $89 \%(80-98)$ & $1.4(0.5-4.1)$ & .543 & $1.8(0 \cdot 6-5.1)$ & .310 & 4 & $91 \%(82-100)$ & $3.7(0.8-16.6)$ & .086 & $3.3(0.7-15.4)$ & .122 \\
\hline 1b Grade 3 & 19 & 4 & $78 \%(58-98)$ & $2.8(0.9-8.8)$ & .087 & $5.1(1.3-19.8)$ & .017 & 4 & $78 \%(58-98)$ & $9.1(2.0-40.7)$ & .004 & $8.8(1.9-40.1)$ & .005 \\
\hline 1c Grade 1 & 63 & 8 & $87 \%(78-96)$ & $1.6(0.6-4.0)$ & .331 & $1.3(0.5-3.3)$ & .565 & 3 & $95 \%(89-100)$ & $2.0(0.4-9.8)$ & .401 & $1.0(0.8-16.8)$ & .981 \\
\hline 1c Grade2 & 26 & 6 & $77 \%(61-93)$ & $2.8(1.0-7.7)$ & .046 & $2.0(0.7-5.6)$ & .185 & 5 & $81 \%(65-96)$ & $7.7(1.8-32.1)$ & .005 & $3.8(0.8-16.8)$ & .083 \\
\hline
\end{tabular}

aAdjusted for age (continuous), sector of care and risk category.

${ }^{b}$ Adjusted for age (continuous), risk category and radiotherapy.

'Reference category.

Table 2: Number of deaths, overall and five-year disease-specific survival and all cause mortality and endometrial cancer mortality risks according to patient and tumour characteristics.

\begin{tabular}{|c|c|c|c|c|c|c|c|c|c|c|c|c|c|}
\hline & \multirow[b]{2}{*}{$\mathrm{N}$} & \multicolumn{6}{|c|}{ Overall mortality } & \multicolumn{6}{|c|}{ Mortality from endometrial cancer } \\
\hline & & Deaths N & $\begin{array}{l}5-\text { y e a r } \\
\text { s u r v i v a I } \\
(95 \% \text { Cl) }\end{array}$ & $\begin{array}{l}\text { Unadjusted } \\
\text { HR }(95 \% \mathrm{Cl})\end{array}$ & $P$-value & $\begin{array}{l}\text { A d j u s t e d } \\
\mathrm{H} \\
(95 \% \mathrm{Cl})^{\mathrm{a}}\end{array}$ & $P$-value & Deaths N & $\begin{array}{l}5-\text { y e a r } \\
\text { s u r v i v a I } \\
(95 \% \text { Cl) }\end{array}$ & $\begin{array}{l}\text { Unadjusted } \\
\operatorname{HR}(95 \% \mathrm{Cl})\end{array}$ & $P$-value & $\begin{array}{l}\text { Adjusted HR } \\
(95 \% \mathrm{Cl})^{\mathrm{b}}\end{array}$ & $P$-value \\
\hline \multicolumn{14}{|l|}{ All patients } \\
\hline None & 87 & 11 & $87 \%(80-94)$ & $1^{\mathrm{c}}$ & & $1^{\mathrm{c}}$ & & 5 & $94 \%(89-99)$ & $1^{c}$ & & $1^{c}$ & \\
\hline Brachytherapy & 94 & 8 & $91 \%(86-97)$ & $0.7(0.3-1.7)$ & .388 & $\begin{array}{ll}1.1 & (0.4- \\
2.8)\end{array}$ & .892 & 5 & $94 \%(90-99)$ & $0.9(0.3-3.2)$ & .899 & $1.3(0.4-4.8)$ & .667 \\
\hline $\begin{array}{l}\text { External } \\
\text { Brachytherapy }\end{array}$ & 89 & 14 & $84 \%(76-92)$ & $1.3(0.6-2.9)$ & .480 & $\begin{array}{l}3.2 \\
8.7)\end{array}$ & .020 & 9 & $89 \%(82-96)$ & $1.9(0.6-5.6)$ & .260 & $3.6(1.0-13.4)$ & .059 \\
\hline \multicolumn{14}{|c|}{ Low risk (myometrial invasion $<50 \%$, grade $1-2$ ) } \\
\hline None & 61 & 6 & $90 \%(82-97)$ & $1^{c}$ & & $1^{c}$ & & 2 & $\begin{array}{l}97 \% \\
100)\end{array}$ & $1^{c}$ & & $1^{c}$ & \\
\hline Brachytherapy & 75 & 5 & $93 \%(88-99)$ & $0.7(0.2-2.2)$ & .426 & $\begin{array}{l}1.6 \\
1.3))\end{array}$ & .476 & 2 & $\begin{array}{l}97 \% \quad(93- \\
100)\end{array}$ & $0.8(0.1-5.7)$ & .832 & $1.7(0.2-13.9)$ & 642 \\
\hline $\begin{array}{l}\text { External } \\
\text { Brachytherapy }\end{array}$ & 26 & 4 & $84 \%(70-99)$ & $1.7(0.5-5.9)$ & .639 & $\begin{array}{ll}6.4 \\
30.2)\end{array}$ & .020 & 3 & $\begin{array}{l}89 \% \\
100)\end{array}$ & $3.7(0.6-22.4)$ & .149 & $9.4(1.0-86.7)$ & .047 \\
\hline \multicolumn{14}{|c|}{ High risk (myometrial invasion $<50 \%$, grade 3 or myometrial invasion $>=50 \%$, grade $1-2$ ) } \\
\hline None & 26 & 5 & $80 \%(65-96)$ & $1^{\mathrm{c}}$ & & $1^{c}$ & & 3 & $\begin{array}{l}87 \% \\
100)\end{array}$ & $1^{c}$ & & $1^{c}$ & \\
\hline Brachytherapy & 19 & 3 & $\begin{array}{l}84 \% \\
100)\end{array}$ & $0.8(0.2-3.5)$ & .802 & $\begin{array}{ll}1.0 & (0.2- \\
4.3)\end{array}$ & .973 & 3 & $\begin{array}{l}84 \% \\
100)\end{array}$ & $1.4(0.3-6.9)$ & .682 & $1.6(0.3-8.1)$ & .564 \\
\hline $\begin{array}{l}\text { External +/- } \\
\text { Brachytherapy }\end{array}$ & 63 & 10 & $90 \%(74-93)$ & $0.9(0.3-2.5)$ & .792 & $\begin{array}{ll}1.7 \\
6.3)\end{array}$ & .396 & 6 & $90 \%(82-98)$ & $0.9(0.2-3.5)$ & .838 & $1.9(0.4-9.1)$ & .453 \\
\hline
\end{tabular}

adjusted for age (continuous), tumour risk category and sector of care

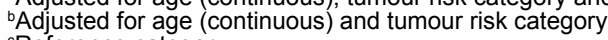

cReference category

Table 3: Number of deaths, overall and five-year disease-specific survival and all cause mortality and endometrial cancer mortality risks according to type of radiotherapy for low risk and high risk patients.

cell or papillary tumours ( $\mathrm{n}=3$ and $\mathrm{n}=7$, respectively), the results were not significantly modified.

\section{Discussion}

This study confirms the findings of previous studies and showed that radiotherapy does not improve disease specific or overall survival in patients with early stage endometrial cancer. More importantly, we observed that external radiotherapy, with or without brachytherapy, are associated with an increased overall and endometrial cancer mortality risk among patients with well or moderately differentiated superficially invasive endometrial cancer.
External radiotherapy has clearly shown its importance in reducing loco-regional recurrence $[9,12,15,19,20,21,22]$.

Two recent randomised controlled trials showed that adding external radiotherapy to surgery for stage I endometrial cancer reduced recurrence rates from approximately $12-15 \%$ to $3-4 \%[9,10]$. However, the effect of radiotherapy on overall and disease specific survival is less well understood. Before publication of the results of the two randomised trials, the available literature showed ambiguous results; some studies reported non-significant trends towards poorer survival rates among 
Citation: Tebeu PM, Verkooijen HM, Popowski Y, Bouchardy C, Ludicke F, et al. (2011) Impact of External Radiotherapy on Survival after Stage I Endometrial Cancer: Results from a Population-Based Study. J Cancer Sci Ther 3: 041-046. doi:10.4172/1948-5956.1000055

women who were treated with external radiotherapy [16,23], whereas others observed improved survival among irradiated women $[3,24]$.

Aalders et al. [8] treated all stage I patients with brachytherapy and then randomised them to external radiotherapy or no further treatment [8]. They found no five-year overall survival difference between patients treated with only brachytherapy compared to those treated with both brachytherapy and external radiotherapy ( $89 \%$ vs. $91 \%$, respectively).

The PORTEC trial's eight- and ten-year updates showed that external radiotherapy strongly reduces the risk of loco-regional recurrence among women with stage I disease (superficial invasion grade 2-3 and deep invasion grade 1-2). However, no significant survival differences were found between irradiated and non-irradiated patients. In fact, there was a non-significant reduced risk of death from endometrial cancer among patients who did not receive radiotherapy (hazard Ratio 0.7, 95\% CI 0.4-1.2) [15,22,25].

In the randomised trial by the Gynecologic Oncology Group, patients with superficially and deeply invasive endometrial cancer limited to the uterus and patients with endometrial cancer showing microscopic invasion of the cervix were randomised to postoperative external radiotherapy and surgery only. There was no significant survival difference between the two study arms. However, among patients with high-risk lesions, there was a non-significant trend towards better overall and disease specific survival among irradiated patients, whereas among women with low-risk tumours (superficial myometrial invasion, grades 1 and 2), there was a 2.4-fold (non-significant) increased risk of dying from endometrial cancer.

Our population-based data are consistent with the trends observed in the two most recent randomised trials $[9,10]$. Adjuvant radiotherapy might do more harm than good in a small minority of patients. Recently, the harm and benefit of adjuvant radiotherapy in intermediate risk endometrial cancer has been weighed [26]. They conclude that out of every 1000 women, 4 will die because of radiotherapy sec. We have included that reference in the text. Nevertheless, we are the first to report significantly increased overall and endometrial cancer mortality risk among low-risk patients. However, our study is not randomised, and consequently, there are baseline differences between the patients who received no radiotherapy, brachytherapy or external radiotherapy. Although we adjusted our models for the most important prognostic factors (age, myometrial invasion and grade), we were unable to adjust for other prognostic factors, such as lymphovascular invasion or the diameter of the tumour. Creutzberg et al. [27] showed that in combination with differentiation and myometrial invasion, lymphovascular invasion is not an independent prognostic factor; however, we cannot determine whether not considering that parameter influenced the results [27].

In addition to a lack of survival benefit, the randomised controlled trials also showed a significant increase in complications among irradiated patients and it can be assumed that external radiotherapy affects long-term quality of life as well $[9,10]$.

Additionally, patients who were treated with external radiotherapy and developed a vaginal recurrence have a significantly lower chance of recovering from this relapse than patients who were initially treated with surgery ( $5 \%$ vs. $30 \%$, respectively) $[13,14,25,27,28]$.

As a result, a more effective strategy might be to reserve radiation therapy for patients who develop a relapse.

In conclusion, our population-based data support the opinion of some authors that external radiotherapy should be discouraged in patients with stage I endometrial cancer, except for poorly differentiated, deeply invasive tumours [29-32].

\section{References}

1. Greenlee RT, Hill-Harmon MB, Murray T, Thun M (2001) Cancer statistics, 2001. CA Cancer J Clin 51: 15-36.

2. Parkin DM, Whelan SL, Ferlay J, Raymond L, Young J, et al. (1997) Cancer Incidence in Five Continents Vol. VII International Agency for Research on Cancer. IARC Scientific Publications.

3. Ayhan A, Taskiran C, Celik C, Aksu T, Yuce K (2002) Surgical stage II endometrial cancer: analysis of treatment outcomes, prognostic factors and failure patterns. Eur J Gynaecol Oncol 23: 553-556.

4. Tebeu PM, Popowski GY, Verkooijen HM, Casals J, Lüdicke F, et al., (2003) Impact of peritoneal cytology on survival of endometrial cancer patients treated with surgery and radiotherapy. Br J Cancer 89 : 2023-2026.

5. Konski A, Domenico D, Tyrkus M, Irving D, Neisler J, et al. (1996) Prognostic characteristics of surgical stage I endometrial adenocarcinoma. Int J Radiat Oncol Biol Phys 35: 935-940.

6. Eltabbakh GH (2002) Analysis of survival after laparoscopy in women with endometrial carcinoma. Cancer 95: 1894-1901.

7. Blake P, Swart AM, Orton J, Kitchener H, Whelan T, et al. (2009) Adjuvan external beam radiotherapy in the treatment of endometrial cancer (MRC ASTEC and NCIC CTG EN.5 randomised trials): pooled trial results, systematic review, and meta-analysis. Lancet 373: 137-146.

8. Aalders J, Abeler V, Kolstad P, Onsrud M (1980) Postoperative external irradiation and prognostic parameters in stage I endometrial carcinoma: clinical and histopathologic study of 540 patients. Obstet Gynecol 56: 419-427.

9. Keys HM, Roberts JA, Brunetto VL, Zaino RJ, Spirtos NM, et al. (2004) A phase III trial of surgery with or without adjunctive external pelvic radiation therapy in intermediate risk endometrial adenocarcinoma: a Gynecologic Oncology Group study. Gynecol Oncol 92: 744-751.

10. Creutzberg CL, van Putten WL, Koper PC, Lybeert ML, Jobsen JJ, et al. (2000) Surgery and postoperative radiotherapy versus surgery alone for patients with stage-1 endometrial carcinoma: multicentre randomised trial. PORTEC Study Group. Post Operative Radiation Therapy in Endometrial Carcinoma. Lance 355: 1404-1411.

11. Ackerman I, Malone S, Thomas G, Franssen E, Balogh J, et al. (1996) Endometrial carcinoma--relative effectiveness of adjuvant irradiation vs therapy reserved for relapse. Gynecol Oncol 60: 177-183.

12. Graham J (1971) The value of preoperative or postoperative treatment by radium for carcinoma of the uterine body. Surg Gynecol Obstet 132: 855-860.

13. Sears JD, Greven KM, Hoen HM, Randall ME (1994) Prognostic factors and treatment outcome for patients with locally recurrent endometrial cancer. Cancer 74: 1303-1308

14. Salazar OM, Feldstein ML, DePapp EW, Bonfiglio TA, Keller BE, et al. (1977) Endometrial carcinoma: analysis of failures with special emphasis on the use of initial preoperative external pelvic radiation. Int J Radiat Oncol Biol Phys 2 . 1101-1107.

15. Creutzberg CL, van Putten WL, Koper PC, Lybeert ML, Jobsen JJ, et al (2003) Survival after relapse in patients with endometrial cancer: results from a randomized trial. Gynecol Oncol 89: 201-209.

16. Tebeu PM, Popowski Y, Verkooijen HM, Bouchardy C, Ludicke F, et al. (2004) Positive peritoneal cytology in early-stage endometrial cancer does not influence prognosis. Br J Cancer 91: 720-724.

17. ICD-O (1976) International classification of diseases for oncology 1st edition ed Geneva: World Health Organization

18. Brémond A, Bataillard A, Thomas L, Achard JL, Fervers B, et al. (2002) [Standards, Options and Recommendations 2000 for the management of patients with endometrial cancer (non-metastatic) (abridged report)]. Gynecol Obstet Fertil 30: 902-916.

19. Marchetti DL, Caglar H, Driscoll DL, Hreshchyshyn MM (1990) Pelvic radiation in stage I endometrial adenocarcinoma with high-risk attributes. Gynecol Onco 37: $51-54$

20. Piver MS, Hempling RE (1990) A prospective trial of postoperative vagina radium/cesium for grade $1-2$ less than $50 \%$ myometrial invasion and pelvic 
Citation: Tebeu PM, Verkooijen HM, Popowski Y, Bouchardy C, Ludicke F, et al. (2011) Impact of External Radiotherapy on Survival after Stage I Endometrial Cancer: Results from a Population-Based Study. J Cancer Sci Ther 3: 041-046. doi:10.4172/1948-5956.1000055

radiation therapy for grade 3 or deep myometrial invasion in surgical stage endometrial adenocarcinoma. Cancer 66: 1133-1138

21. Barhum M, Stein M, Ronsenblatt E, Dale J, Kuten A (1993) Pathological stage I endometrial carcinoma: the role for adjuvant radiotherapy. Tumori 79: 405-409.

22. Scholten AN, van Putten WL, Beerman H, Smit VT, Koper PC, et al. (2005) Postoperative radiotherapy for Stage 1 endometrial carcinoma: long-term outcome of the randomized PORTEC trial with central pathology review. Int $\mathrm{J}$ Radiat Oncol Biol Phys 63: 834-838

23. Fanning J, Evans MC, Peters AJ, Samuel M, Harmon ER, et al. (1987) Adjuvant radiotherapy for stage I, grade 2 endometrial adenocarcinoma and adenoacanthoma with limited myometrial invasion. Obstet Gynecol 70: 920922

24. Straughn JM Jr, Huh WK, Kelly FJ, Leath CA 3rd, Kleinberg MJ, et al. (2002) Conservative management of stage I endometrial carcinoma after surgical staging. Gynecol Oncol 84: 194-200.

25. Roovers JP, van der Vaart $\mathrm{CH}$, van der Bom JG, van Leeuwen JH, Scholten PC, et al. (2004) A randomised controlled trial comparing abdominal and vaginal prolapse surgery: effects on urogenital function. BJOG 111: 50-56.

26. Knops AM, Goossens A, Burger MP, Stalpers LJ, Ubbink DT (2009) A tool to balance benefit and harm when deciding about adjuvant therapy. $\mathrm{Br} \mathrm{J}$ Cancer 100: 913-917.

27. Creutzberg $C L$, van Putten WL, Wárlám-Rodenhuis $C C$, van den Bergh $A C$, de Winter KA, et al. (2004) Outcome of high-risk stage IC, grade 3, compared with stage I endometrial carcinoma patients: the Postoperative Radiation Therapy in Endometrial Carcinoma Trial. J Clin Oncol 22: 1234-1241.

28. Hamajima N, Hirose K, Tajima K, Rohan T, Calle EE, et al. (2002) Alcohol tobacco and breast cancer--collaborative reanalysis of individual data from 53 epidemiological studies, including 58,515 women with breast cancer and 95,067 women without the disease. Br J Cancer 87: 1234-1245.

29. Burger MP (2001) Management of stage 1 endometrial carcinoma Postoperative radiotherapy is not justified in women with medium risk disease. BMJ 322: 568-569.

30. Berman ML (2004) Adjuvant radiotherapy following properly staged endometrial cancer: what role? Gynecol Oncol 92: 737-739.

31. Lin LL, Mutch DG, Rader JS, Powell MA, Grigsby PW (2007) External radiotherapy versus vaginal brachytherapy for patients with intermediate risk endometrial cancer. Gynecol Oncol 106: 215-220.

32. Kong A, Powell M, Blake P (2008) The role of postoperative radiotherapy in carcinoma of the endometrium. Clin Oncol (R Coll Radiol) 20: 457-462. 